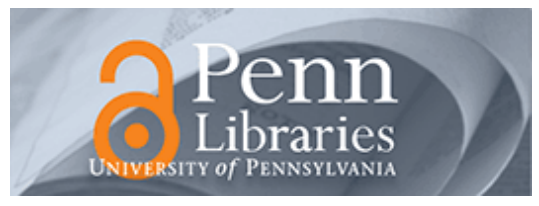

University of Pennsylvania

ScholarlyCommons

Finance Papers

Wharton Faculty Research

$10-2011$

\title{
How Q and Cash Flow Affect Investment without Frictions: An Analytic Explanation
}

Andrew B. Abel

University of Pennsylvania

Janice C. Eberly

Follow this and additional works at: https://repository.upenn.edu/fnce_papers

Part of the Finance Commons, and the Finance and Financial Management Commons

Recommended Citation

Abel, A. B., \& Eberly, J. C. (2011). How Q and Cash Flow Affect Investment without Frictions: An Analytic

Explanation. The Review of Economic Studies, 78 (4), 1179-1200. http://dx.doi.org/10.1093/restud/rdr006

This paper is posted at ScholarlyCommons. https://repository.upenn.edu/fnce_papers/162

For more information, please contact repository@pobox.upenn.edu. 


\title{
How Q and Cash Flow Affect Investment without Frictions: An Analytic Explanation
}

\begin{abstract}
We derive a closed-form solution for Tobin's $Q$ in a stochastic dynamic framework. We show analytically that investment is positively related to Tobin's $Q$ and cash flow, even in the absence of adjustment costs or financing frictions. Both $Q$ and investment move in the same direction as expected revenue growth, so changes in expected revenue growth induce $Q$ and investment to comove positively. Similarly, shocks to current cash flow, arising from shocks to the user cost of capital in our model, cause investment and cash flow per unit of capital to comove positively. Furthermore, we show that this alternative mechanism for the relationship among investment, $Q$, and cash flow delivers larger cash flow effects for smaller- and faster-growing firms, as observed in the data. Moreover, the empirically small sensitivity of investment to Tobin's $Q$ does not imply implausibly large adjustment costs in our model (since there are no adjustment costs). Calibrating the model generates values of $Q$ similar to those in the data; investment is more sensitive to cash flow than it is to $Q$, and both responses are of empirically plausible magnitudes.
\end{abstract}

\section{Keywords}

investment, tobin's Q, cash flow

Disciplines

Economics | Finance | Finance and Financial Management 


\title{
How $Q$ and Cash Flow Affect Investment without Frictions: An Analytic Explanation $^{1}$
}

\author{
Andrew B. Abel \\ The Wharton School of the University of Pennsylvania \\ National Bureau of Economic Research \\ Janice C. Eberly \\ Kellogg School of Management, Northwestern University \\ National Bureau of Economic Research
}

August 2008, current version November 2008

\footnotetext{
${ }^{1}$ Earlier versions of this paper circulated under the title " $Q$ Theory without Adjustment Costs \& Cash Flow Effects without Financing Constraints." We thank Joao Gomes, Philipp Illeditsch, Richard Kihlstrom, Michael Michaux, Stavros Panageas, Julien Prat, and Ken West for helpful comments, as well as seminar participants at the Federal Reserve Bank of Kansas City, New York University, Stanford University, University of California at San Diego, University of Chicago, University of Wisconsin, University of Southern California, the Penn Macro Lunch Group, the Workshop on Firms' Dynamic Adjustment in Bergamo, Italy, and the Society for Economic Dynamics meeting in Florence, Italy.
} 


\begin{abstract}
We derive a closed-form solution for Tobin's $Q$ in a stochastic dynamic framework. We show analytically that investment is positively related to Tobin's $Q$ and cash flow, even in the absence of adjustment costs or financing frictions. In the spirit Brainard and Tobin (1968), shocks to firm growth move $Q$ and investment together since both increase with positive shocks to revenue growth. Similarly, shocks to current cash flow, arising from shocks to the user cost of capital in our model, cause investment and cash flow per unit of capital to comove positively. Furthermore, we show that this alternative mechanism for the relationship among investment, $Q$, and cash flow delivers larger cash flow effects for smaller and faster-growing firms, as observed in the data. Moreover, the empirically small correlation between investment and Tobin's $Q$ does not imply implausibly large adjustment costs in our model (since there are no adjustment costs), but simply reflects a common response to changes in the firm's revenue growth.
\end{abstract}


Regressions of investment on Tobin's $Q$ and cash flow typically yield a small positive coefficient on $Q$ and a significant positive coefficient on cash flow. The small coefficient on $Q$ is interpreted as evidence of strongly convex adjustment costs, and the significant cash flow coefficient is interpreted as evidence of the importance of financing constraints facing firms. In this paper we develop and analyze an economic model in which both of these interpretations are false. In particular, we develop a simple neoclassical model without adjustment costs and without financing constraints. We show analytically that the investment-capital ratio depends positively on Tobin's $Q$ and on cash flow per unit of capital. The coefficient on $Q$ can be small, yet it cannot be interpreted as strongly convex adjustment costs, because adjustment costs are excluded from model. The positive effect of cash flow on investment cannot be interpreted as a reflection of financing constraints because there are no financing constraints in the model. In our model, these effects arise because Tobin's $Q$ reflects expectations about future revenue growth, while cash flow reflects the effects of the user cost of capital. Since both of these underlying shocks (revenue growth and the user cost of capital) drive investment, investment will be correlated with both $Q$ and cash flow.

James Tobin (1969) introduced the ratio of the market value of a firm to the replacement cost of its capital stock - a ratio that he called " $Q$ " - to measure the incentive to invest in capital. ${ }^{1}$ Tobin's $Q$, as it has become known, is the empirical implementation of Keynes's (1936) notion that capital investment becomes more attractive as the value of capital increases relative to the cost of acquiring the capital. Neither Keynes nor Tobin provided a formal decision-theoretic analysis underlying the $Q$ theory of investment. Lucas and Prescott (1971) developed a rigorous analysis of the capital investment decision in the presence of convex costs of adjustment, and observed that the market value of capital can be an important element of the capital

\footnotetext{
${ }^{1}$ Brainard and Tobin (1968) introduced the idea that a firm's investment should be positively related to the ratio of its market value to the replacement value of its capital stock, though they did not use the letter $Q$ to denote this ratio.
} 
investment decision, though they did not explicitly make the link to Tobin's $Q$.

The link between convex costs of adjustment and the $Q$ theory of investment was made explicitly by Mussa (1977) in a deterministic framework and by Abel (1983) in a stochastic framework, though the papers based on convex adjustment costs focused on marginal $Q$ - the ratio of the value of an additional unit of capital to its acquisition cost - rather than the concept of average $Q$ introduced by Tobin. Hayashi (1982) bridged the gap between the concept of marginal $Q$ dictated by the models based on convex adjustment costs and the concept of average $Q$, which is readily observable, by providing conditions, in a deterministic framework, under which marginal $Q$ and average $Q$ are equal. Specifically, marginal $Q$ and average $Q$ are equal for a competitive firm with a constant-returns-to-scale production function provided that the adjustment cost function is linearly homogeneous in the rate of investment and the level of the capital stock. Abel and Eberly (1994) extended Hayashi's analysis to the stochastic case and also analyzed the relationship between average $Q$ and marginal $Q$ in some special situations in which these two variables are not equal.

In the current paper, we develop a new theoretical basis for the empirical relationship between investment and $Q$ that differs from the literature based on convex adjustment costs in two major respects. First, we will dispense with adjustment costs completely, and assume that a firm can instantaneously and completely adjust its capital stock by purchasing or selling capital at an exogenous price, without having to pay any costs of adjustment. Second, average $Q$ and marginal $Q$ will differ from each other. In the literature based on convex adjustment costs, when average $Q$ and marginal $Q$ differ, it is marginal $Q$ that is relevant for the investment decision, which is unfortunate since average $Q$ is more readily observable than marginal $Q$. In the current paper, it is average $Q$ that is related to the rate of investment; in fact, marginal $Q$ is identically equal to one in this model and hence it cannot be related to fluctuations in investment.

Both average $Q$ and marginal $Q$ would be identically equal to one for a competitive firm with a constant-returns-to-scale production function that can purchase and sell 
capital at an exogenous price without any cost of adjustment. In order for average $Q$ to exceed one, the firm must earn rents through the ownership or exploitation of a scarce factor. In the traditional $Q$-theoretic literature, the convex adjustment cost technology is the source of rents for a competitive firm with a constant-returns-toscale production function. In the current paper, which has no convex adjustment costs, rents are earned as a result of monopoly power or as a result of decreasing returns to scale in the production function. A contribution of this paper is to show that not only do these rents cause average $Q$ to exceed one, but that fluctuations in average $Q$ are positively related to fluctuations in the investment-capital ratio. Thus, our mechanism for a "Q-theoretic" model remains in the spirit of Brainard and Tobin since the present value of future rents is correlated with optimal investment; however, we show that adjustment costs are not necessary to this finding.

Lindenberg and Ross (1981) derive the value of Tobin's $Q$ for a firm with monopoly power that does not face convex costs of adjustment. They focus on the extent to which Tobin's $Q$ provides a measure of, or at least a bound on, monopoly power. Unlike our paper, they do not emphasize the link the between investment and Tobin's $Q$. More importantly, their analysis is conducted in a deterministic framework that does not admit interesting time-series variation in Tobin's $Q .{ }^{2}$ A major contribution of our paper, relative to this earlier work, is that we embed the firm in a stochastic environment that is rich enough to generate interesting time-series variation in Tobin's $Q$, yet tractable enough to be used to derive a closed-form solution for Tobin's $Q$. This solution for Tobin's $Q$, with interesting time-series variation, is a critical ingredient to our study of the predicted effect on investment of a change in Tobin's $Q$. Similarly, Schiantarelli and Georgoutsos (1990) specify a model of investment with monopolistic competition, but also allow for quadratic costs of adjusting capital. They show that in addition to a richer dynamic structure, ${ }^{3}$ output enters the equation relating invest-

\footnotetext{
${ }^{2}$ Their footnote 9 outlines an extension to the stochastic case, but does not derive a closed-form solution for Tobin's $Q$ that has interesting stochastic variation.

${ }^{3}$ Future values of investment and $Q$ enter the equation, in addition to the usual current value of Tobin's $Q$.
} 
ment and Tobin's $Q$. This gives a rationale for output to appear in the investment equation, but the mechanism is distinct from the one that generates a cash flow effect in this paper, since the mechanism here requires no adjustment costs at all. ${ }^{4}$

An important implication of traditional $Q$-theoretic models based on convex adjustment costs is that (marginal) $Q$ is a sufficient statistic for the rate of investment. Other variables should not have any additional explanatory for investment if $Q$ is an explanatory variable. However, many empirical studies of investment and $Q$ have rejected this implication by finding that cash flow has a significant effect on investment, even if $Q$ is included as an explanatory variable. This finding has been interpreted by Fazzari, Hubbard, and Petersen (1988) and others as evidence of financing constraints facing firms. In the model we develop here, there are no financing constraints - capital markets are perfect - yet investment is positively related to cash flow in addition to $Q$. Investment and cash flow (per unit of capital) positively comove in our model because both react in the same direction to shocks to the user cost of capital. Furthermore, in our model this "cash flow effect" on investment is larger for smaller and faster-growing firms, as has been found empirically; it is usually argued that this differential cash flow effect across groups of firms strengthens the financing constraints interpretation, but in this model these differential effects exist in perfect capital markets.

The interpretation of cash flow effects as evidence of financing constraints is also called into question by Gomes (2001); in his quantitative model, optimal investment is sensitive to both Tobin's $Q$ and cash flow, whether or not a cost of external finance is present. Similarly, Cooper and Ejarque (2003) numerically solve a model with quadratic adjustment costs and a concave revenue function, and also find that

\footnotetext{
${ }^{4}$ In particular, because of the convex adjustment costs, marginal $Q$ is the appropriate indicator of investment in their model, but Tobin's $Q$ is observable and appears in the estimated investment equation. The output-capital ratio appears in the estimated investment equation to correct for mismeasurement; it proxies for the gap between (measured) Tobin's $Q$ and marginal $Q$. The output-capital ratio therefore appears with a negative sign in their specification to capture the scale of the firm, and hence the gap between marginal and average $Q$.
} 
investment is sensitive to both Tobin's $Q$ and cash flow in the absence of financing constraints. In addition, they find that adding a fixed cost of access to capital markets does not improve the fit of the model and they conclude the cash flow sensitivity of investment reflects market power rather than financial constraints. Alti (2003) develops a continuous-time model of a firm facing quadratic adjustment costs and with a revenue function that is concave in the capital stock and subject to a multiplicative productivity shock. The logarithm of the shock reverts to an unknown mean and firms update their estimates of the mean by observing realizations of cash flow over time. For young firms, the estimate of the mean is noisy and Tobin's $Q$ provides a noisy measure of long-run prospects that are important for investment. ${ }^{5}$ For these firms especially, observations on cash flow provide important evidence that can change the estimate of the mean level of productivity and hence affect investment. ${ }^{6}$ Gomes (2001), Cooper and Ejarque (2003), and Alti (2003) numerically compute Tobin's $Q$ because they cannot analytically solve for the value of the firm. A contribution of our current paper is that we provide a closed-form solution for the value of the firm and hence for Tobin's $Q$. The importance of the closed-form solution is that it allows a straightforward analytic description of the statistical relationship among investment, Tobin's $Q$ and cash flow.

The model we develop is designed to be as simple as possible, yet rich enough to deliver interesting time-series variation in the investment-capital ratio, Tobin's $Q$, and the ratio of cash flow to the capital stock. Section 1 presents the firm's net revenue as an isoelastic function of its capital stock. The revenue function is subject to

\footnotetext{
${ }^{5}$ Similarly, Erickson and Whited (2000) find that when controlling for measurement error in a flexible way, the evidence for a cash flow effect on investment disappears in their sample.

${ }^{6}$ A related, but different, interchange has occurred between Kaplan and Zingales (1997, 2000) and Fazzari, Hubbard, and Petersen (2000). Kaplan and Zingales have argued both empirically and theoretically that the sensitivity of investment to cash flow is not a reliable indicator of the degree of financial constraints. This interchange is distinct from the model presented here, since we have assumed no financial constraints at all, yet investment is sensitive to cash flow. Empirical work by Gomes, Yaron, and Zhang (2006) also finds no evidence of financing constraints facing firms.
} 
stochastic shocks that change its growth rate at random points in time. The optimal capital stock is derived in Section 1 and the consequent optimal rate of investment is derived in Section 2. Section 3 derives the value of the firm and Tobin's $Q$. The relationship among the investment-capital ratio, Tobin's $Q$, and the cash flow-capital stock ratio is analyzed in Section 4, and the effects of firm size and growth on this relationship are analyzed in Section 5. Concluding remarks are presented in Section 6.

\section{The Decision Problem of the Firm}

Consider a firm that uses capital, $K_{t}$, and labor, $N_{t}$, to produce nonstorable output, $Y_{t}$, at time $t$ according to the production function

$$
Y_{t}=A_{t}\left(K_{t}^{\gamma} N_{t}^{1-\gamma}\right)^{s}
$$

where $A_{t}$ is productivity at time $t, 0<s \leq 1$ is the degree of returns to scale $(s=1$ for constant returns to scale) and $0<\gamma<1$. The inverse demand function for the firm's output is

$$
P_{t}=h_{t} Y_{t}^{-\frac{1}{\varepsilon}}
$$

where $h_{t}>0$ and $\varepsilon>1$ is the price elasticity of demand. At time $t$, the firm chooses labor, $N_{t}$, to maximize revenue net of labor costs, $R_{t}=P_{t} Y_{t}-w_{t} N_{t}$, where $w_{t}$ is the wage rate at time $t$. It is straightforward, but tedious, to show that if the firm uses 
the optimal amount of labor, $N_{t}$, then revenue net of labor costs is ${ }^{7}$

$$
R_{t}=Z_{t}^{1-\alpha} K_{t}^{\alpha}
$$

where $Z_{t} \equiv \chi^{\frac{1}{1-\alpha}}\left(h_{t} w_{t}^{-(1-\gamma) s\left(1-\frac{1}{\varepsilon}\right)} A_{t}^{1-\frac{1}{\varepsilon}}\right)^{\frac{\varepsilon}{\varepsilon-\varepsilon s+s}}$ reflects productivity, the demand for the firm's output, and the wage rate, $\alpha \equiv \frac{\gamma s\left(1-\frac{1}{\varepsilon}\right)}{1-(1-\gamma) s\left(1-\frac{1}{\varepsilon}\right)}>0$, and $\chi>0$ is a constant. Since $Z_{t}$ is an isoelastic function of $h_{t}, A_{t}$, and $w_{t}$ (with different, but constant elasticities, with respect to these three variables), the growth rate of $Z_{t}$ is a weighted average of the growth rates of $h_{t}, A_{t}$, and $w_{t}$, with the weights equal to the corresponding elasticities. For a competitive firm with constant returns to scale $(\varepsilon=\infty$ and $s=1), \alpha=1$. However, if the firm has some monopoly power $(\varepsilon<\infty)$ or if it faces decreasing returns to scale $(s<1)$, then $\alpha<1$ and hence net revenue is a strictly concave function of the capital stock. This concavity implies that firm will earn positive rents. Henceforth, we confine attention to the case with $\alpha<1$.

The variable $Z_{t}$ is exogenous to the firm and follows a geometric Brownian motion with a time-varying drift, $\mu_{t}$, so

$$
\frac{d Z_{t}}{Z_{t}}=\mu_{t} d t+\sigma d z
$$

If the growth rate $\mu_{t}$ were constant over time, the future growth prospects for the firm would always look the same, and, as we will show, there would be no time-series variation in the expected present value of the firm's future operating profits relative to current operating profits (more precisely, the present value in equation (29) would

\footnotetext{
${ }^{7}$ Use the production function in equation (1) and the inverse demand function in equation (2) to write net revenue as $R_{t}=g_{t} N_{t}^{\nu}-w_{t} N_{t}$, where $g_{t} \equiv h_{t} A_{t}^{1-\frac{1}{\varepsilon}} K_{t}^{\gamma s\left(1-\frac{1}{\varepsilon}\right)}$ and $\nu \equiv(1-\gamma) s\left(1-\frac{1}{\varepsilon}\right)$. Differentiating this expression for $R_{t}$ with respect to $N_{t}$ and setting the derivative equal to zero yields $\nu g_{t} N_{t}^{\nu-1}=w_{t}$, which can be used to write net revenue as $R_{t}=\frac{1-\nu}{\nu} w_{t} N_{t}=(1-\nu) \nu^{\frac{\nu}{1-\nu}} w_{t}^{-\frac{\nu}{1-\nu}} g_{t}^{\frac{1}{1-\nu}}$. Substitute the definition of $g_{t}$ into the expression for $R_{t}$ and use the definition of $\alpha$ to obtain $R_{t}=\chi\left[w_{t}^{-\nu} h_{t} A_{t}^{1-\frac{1}{\varepsilon}}\right]^{\frac{1}{1-\nu}} K_{t}^{\alpha}$ where $\chi \equiv(1-\nu) \nu^{\frac{\nu}{1-\nu}}$. Use the fact that $1-\alpha=\frac{1-s\left(1-\frac{1}{\varepsilon}\right)}{1-\nu}$ to rewrite the expression for $R_{t}$ as $R_{t}=\left[\chi^{\frac{1}{1-\alpha}}\left(w_{t}^{-\nu} h_{t} A_{t}^{1-\frac{1}{\varepsilon}}\right)^{\frac{1}{1-s\left(1-\frac{1}{\varepsilon}\right)}}\right]^{1-\alpha} K_{t}^{\alpha}$ so $R_{t}=Z_{t}^{1-\alpha} K_{t}^{\alpha}$ where $Z_{t} \equiv \chi^{\frac{1}{1-\alpha}}\left(w_{t}^{-\nu} h_{t} A_{t}^{1-\frac{1}{\varepsilon}}\right)^{\frac{\varepsilon}{\varepsilon-s \varepsilon+s}}$.
} 
be a constant multiple of contemporaneous $Z_{t}$ ). To introduce some interesting, yet tractable, variation in the firm's growth prospects, we assume that the process for $Z_{t}$ follows a regime-switching process ${ }^{8}$ in which a regime is defined by a constant value of the drift $\mu_{t}$. A regime remains in force, that is, the drift remains constant, for a random length of time. A new regime, which is characterized by a new value of the drift, arrives with constant probability $\lambda \geq 0$. The new value of the drift is drawn from an unchanging distribution $F(\widetilde{\mu})$ with support in the interval $\left[\mu_{L}, \mu_{H}\right]$. The values of the drift are i.i.d. across regimes and are independent of the realizations of the other stochastic processes in the model. The value of the firm is finite and is increasing in contemporaneous operating profit for a given value of the capital stock if

$$
E\left\{\frac{1}{r+\lambda-\widetilde{\mu}}\right\}>0
$$

and

$$
E\left\{\frac{\lambda}{r+\lambda-\widetilde{\mu}}\right\}<1,
$$

where $r$ is the discount rate of the firm.

Henceforth, we assume that the following condition holds.

\section{Condition $1 r>\mu_{H}$.}

Condition 1, along with the fact that $\lambda \geq 0$, implies that equations (5) and (6) both hold.

The firm can purchase or sell capital instantaneously and frictionlessly, without any costs of adjustment, at a constant price that we normalize to one. Because there are no costs of adjustment, we can use Jorgenson's (1963) insight that the optimal path of capital accumulation can be obtained by solving a sequence of static decision

\footnotetext{
${ }^{8}$ Eberly, Rebelo, and Vincent (2008) find an important role for regime-switching in empirical investment equations. Specifically, they report that a "single-regime model ... cannot explain the role of lagged investment in investment regressions" but "the performance of the model can be greatly improved by a regime-switching component" for the exogenous stochastic process. (p. 11)
} 
problems using the concept of the user cost of capital. With the price of capital constant and equal to one, the user cost of capital, $v_{t}$, is

$$
v_{t} \equiv r+\delta_{t}
$$

where $\delta_{t}$ is the depreciation rate of capital. We will discuss the stochastic properties of $\delta_{t}$ later in this section. For the specific goal of studying the relationship between investment and Tobin's $Q$, we could simply assume that $\delta_{t}$ is constant. Variation in $\delta_{t}$ will be useful when we examine the effect of cash flow on investment.

At time $t$ the firm chooses the capital stock $K_{t}$ to maximize operating profit, $\pi_{t}$, which equals net revenue less the user cost of capital

$$
\pi_{t} \equiv R_{t}-v_{t} K_{t}=Z_{t}^{1-\alpha} K_{t}^{\alpha}-v_{t} K_{t}
$$

Differentiating equation (8) with respect to $K_{t}$ and setting the derivative equal to zero yields the optimal value of the capital stock

$$
K_{t}=Z_{t}\left(v_{t} / \alpha\right)^{\frac{-1}{1-\alpha}}
$$

Substituting the optimal capital stock from equation (9) into equations (8) and (3), respectively, yields the optimal level of operating profit

$$
\pi_{t}=(1-\alpha) Z_{t}\left(v_{t} / \alpha\right)^{\frac{-\alpha}{1-\alpha}}
$$

and the optimal level of revenue (net of labor cost)

$$
R_{t}=\frac{1}{1-\alpha} \pi_{t}
$$

Empirical investment equations often use a measure of cash flow, normalized by the capital stock, as an explanator of investment. Since $R_{t}$ is defined as revenue net of labor costs, it is cash flow before investment expenditure. Let $c_{t} \equiv R_{t} / K_{t}$ be the cash flow before investment, normalized by the capital stock, and note, for later use, that

$$
c_{t}=\frac{1}{1-\alpha} \frac{\pi_{t}}{K_{t}}=\frac{v_{t}}{\alpha}
$$


where the first equality follows from equation (11) and the second equality follows from equations (9) and (10).

Equations (10) and (11) together imply that an increase in the user cost of capital, $v_{t}$, reduces cash flow, $R_{t}$. Although cash flow falls in response to an increase in the user cost of capital, it does not fall by as much as the capital stock falls. Therefore, an increase in the user cost of capital will increase cash flow per unit of capital. Indeed, equation (12) indicates that cash flow per unit of capital is proportional to the user cost of capital.

It will be convenient to define a variable $M_{t}$ that summarizes the effect of the user cost on the optimal capital stock and operating profit, and to specify the stochastic variation in $M_{t}$ directly. In particular, define

$$
M_{t} \equiv\left(\frac{v_{t}}{\alpha}\right)^{\frac{-\alpha}{1-\alpha}}=\left(\frac{r+\delta_{t}}{\alpha}\right)^{\frac{-\alpha}{1-\alpha}} .
$$

We assume that $M_{t}$ is a martingale and is independent of the parameters and realizations of the process for $Z_{t}$. The assumption that $M_{t}$ is a martingale implies that $\delta_{t}$ is not a martingale. In particular, it implies that the depreciation rate is expected to grow over time. ${ }^{9}$ For the sake of concreteness, we assume that $M_{t}$ is a trendless

\footnotetext{
${ }^{9}$ Note that for $\tau>0,1=E_{t}\left\{\frac{M_{t+\tau}}{M_{t}}\right\}=E_{t}\left\{\left(\frac{v_{t+\tau}}{v_{t}}\right)^{-\frac{\alpha}{1-\alpha}}\right\}>\left[E_{t}\left\{\frac{v_{t+\tau}}{v_{t}}\right\}\right]^{-\frac{\alpha}{1-\alpha}}$, where the first equality follows from the assumption that $M_{t}$ is a martingale, the second equality follows from the definition of $M_{t}$, and the third (in)equality follows from Jensen's inequality. Therefore, $E_{t}\left\{\frac{v_{t+\tau}}{v_{t}}\right\}>1$, which implies that $E_{t}\left\{\delta_{t+\tau}\right\}>\delta_{t}$ so that the depreciation rate is expected to grow over time. This implication is consistent with depreciation rates computed for U.S. private nonresidential fixed assets using the Bureau of Economic Analysis Fixed Asset Tables 4.1 and 4.4 and taking the ratio of annual depreciation to the beginning-of-year net stock of capital. The average depreciation rates for 1950-59, 1970-79, and 1997-2006 are, respectively, 6.3\%, 7.1\%, and 8.2\%. For equipment and software, the corresponding figures are $13.7 \%, 14.2 \%$, and $16.8 \%$, and for structures the corresponding figures are $2.8 \%, 3.0 \%$ and $3.0 \%$.
} 
geometric Brownian motion. Specifically, we assume that ${ }^{10}$

$$
d M_{t}=\sigma_{M} M_{t} d z_{M}
$$

where $\sigma_{M}>0$.

Use the definition of $M_{t}$ in equation (13) to rewrite the expressions for the optimal capital stock and the optimal operating profit in equations (9) and (10), respectively, as

$$
K_{t}=Z_{t} M_{t}^{\frac{1}{\alpha}}
$$

and

$$
\pi_{t}=(1-\alpha) Z_{t} M_{t}
$$

Equations (15), (16) and (11) indicate that the capital stock, operating profit, and revenue are all increasing functions of contemporaneous values of $Z_{t}$ and $M_{t}$ and are independent of $\mu_{t}$, conditional on $Z_{t}$ and $M_{t}$. Thus, regardless of whether firm size is measured by the size of the capital stock, operating profit, or revenue, firm size is increasing in $Z_{t}$ and $M_{t}$, but is independent of $\mu_{t}$. In addition, equations (15) and (16) imply that $\frac{\pi_{t}}{K_{t}}=(1-\alpha) M_{t}^{-\frac{1-\alpha}{\alpha}}$ so that $\frac{\pi_{t}}{K_{t}}$ is a decreasing funtion of $M_{t}$ and hence $\frac{\pi_{t}}{K_{t}}$ is larger for small firms than for large firms.

In Section 2 we examine the firm's investment by analyzing the evolution of the optimal capital stock in equation (15). Then in Section 3 we use the expression for the optimal operating profit in equation (16) to compute the value of the firm.

\section{Investment}

Gross investment is the sum of net investment, $d K_{t}$, and depreciation $\delta_{t} K_{t} d t$. To calculate net investment divided by the capital stock, apply Ito's Lemma to the expression for the optimal capital stock in equation (15) and use the processes for $Z_{t}$

\footnotetext{
${ }^{10}$ Although the process in equation (14) implies that if the initial value of $M_{t}$ is positive, it will remain positive, it does not ensure that $\delta_{t}$ is positive (it implies that $\delta_{t}>-r$ ).
} 
and $M_{t}$ in equations (4) and (14), respectively, to obtain

$$
\frac{d K_{t}}{K_{t}}=\mu_{t} d t+\frac{1}{2} \frac{1-\alpha}{\alpha^{2}} \sigma_{M}^{2} d t+\sigma d z+\frac{1}{\alpha} \sigma_{M} d z_{M}
$$

Adding the depreciation rate of capital, $\delta_{t}$, to net investment per unit of capital in equation (17) yields gross investment per unit of capital

$$
\frac{d I_{t}}{K_{t}} \equiv \frac{d K_{t}}{K_{t}}+\delta_{t} d t=\left(\mu_{t}+\delta_{t}\right) d t+\frac{1}{2} \frac{1-\alpha}{\alpha^{2}} \sigma_{M}^{2} d t+\sigma d z+\frac{1}{\alpha} \sigma_{M} d z_{M}
$$

Investment is a linear function of the growth rate, $\mu_{t}$, the depreciation rate, $\delta_{t}$,

and a mean-zero disturbance, $\sigma d z+\frac{1}{\alpha} \sigma_{M} d z_{M}$, that is independent of $\mu_{t}$ and $\delta_{t}$. If $\mu_{t}$ and $\delta_{t}$, as well as the investment-capital ratio, were observable, then we could use a linear regression to estimate the effects on the investment-capital ratio of $\mu_{t}$ and $\delta_{t}$. In a sufficiently large sample, the coefficients on $\mu_{t}$ and $\delta_{t}$ would both equal one. However, $\mu_{t}$ is not observable and $\delta_{t}$ may not be well measured. We will show in later sections that movements in $\mu_{t}$ are reflected by movements in Tobin's $Q$, and movements in $\delta_{t}$ are reflected by movements in the firm's cash flow per unit of capital and in Tobin's $Q$. Thus, Tobin's $Q$ and cash flow per unit of capital can help to explain investment statistically.

\section{The Value of the Firm and Tobin's $Q$}

The value of the firm, $V_{t}$, is the present value of current and expected future cash flows, net of the cost of current and future investment, and satisfies

$$
r V_{t} d t=E_{t}\left\{R_{t} d t-\left(d K_{t}+\delta_{t} K_{t} d t\right)+d V_{t}\right\}
$$

The left hand side of equation (19) is the required return on the firm over the interval of time from $t$ to $t+d t$, and the right hand side of equation (19) is the expected return over this interval of time. The expected return on the right hand side consists of two components: (1) the expected net cash flow, which equals revenue, $R_{t}$, less gross investment $d K_{t}+\delta_{t} K_{t} d t$ and (2) the expected capital gain or loss reflecting the change in the value of the firm. 
The value of the firm depends on three state variables ${ }^{11}-Z_{t}, M_{t}$, and $\mu_{t}-$ so the value of the firm in equation (19) can be written as $V_{t}=V\left(Z_{t}, M_{t}, \mu_{t}\right)$. To express equation (19) in terms of the state variables, first use equations (11) and (16) to obtain

$$
R_{t}=Z_{t} M_{t}
$$

and use equations (15) and (18) to obtain

$$
E_{t}\left\{d K_{t}+\delta_{t} K_{t} d t\right\}=\left(\mu_{t}+\delta_{t}+\frac{1}{2} \frac{1-\alpha}{\alpha^{2}} \sigma_{M}^{2}\right) Z_{t} M_{t}^{\frac{1}{\alpha}} d t .
$$

Then, to calculate $d V\left(Z_{t}, M_{t}, \mu_{t}\right)$, use Ito's Lemma, equations (4) and (14) for the evolution of $Z_{t}$ and $M_{t}$, respectively, and the stochastic process for $\mu_{t}$ to obtain

$$
\begin{aligned}
E_{t}\left\{d V\left(Z_{t}, M_{t}, \mu_{t}\right)\right\}= & V_{Z} \mu_{t} Z_{t} d t+\frac{1}{2} V_{Z Z} \sigma^{2} Z_{t}^{2} d t+\frac{1}{2} V_{M M} \sigma_{M}^{2} M_{t}^{2} d t \\
& +\lambda\left[E_{t}\left\{V\left(Z_{t}, M_{t}, \widetilde{\mu}\right)-V\left(Z_{t}, M_{t}, \mu_{t}\right)\right\}\right] d t .
\end{aligned}
$$

Equations (20), (21), and (22) allow us to rewrite equation (19) as

$$
\begin{aligned}
r V\left(Z_{t}, M_{t}, \mu_{t}\right)= & Z_{t} M_{t}-\left(\mu_{t}+\delta_{t}+\frac{1}{2} \frac{1-\alpha}{\alpha^{2}} \sigma_{M}^{2}\right) Z_{t} M_{t}^{\frac{1}{\alpha}}+V_{Z} \mu_{t} Z_{t} \\
& +\frac{1}{2} V_{Z Z} \sigma^{2} Z_{t}^{2}+\frac{1}{2} V_{M M} \sigma_{M}^{2} M_{t}^{2}+\lambda\left[E_{t}\left\{V\left(Z_{t}, M_{t}, \widetilde{\mu}\right)-V\left(Z_{t}, M_{t}, \mu_{t}\right)\right\}\right] .
\end{aligned}
$$

In Appendix B, we show that a solution to equation (23) is

$$
V\left(Z_{t}, M_{t}, \mu_{t}\right)=Z_{t} M_{t}^{\frac{1}{\alpha}}+\frac{\omega(1-\alpha) Z_{t} M_{t}}{r+\lambda-\mu_{t}}
$$

where $^{12}$

$$
\omega \equiv\left[E\left\{\frac{r-\widetilde{\mu}}{r+\lambda-\widetilde{\mu}}\right\}\right]^{-1} \geq 1
$$

with strict inequality if $\lambda>0$.

Here we present a heuristic derivation of the value function that has a simple economic interpretation. The value of the firm can be derived by viewing the firm as

\footnotetext{
${ }^{11}$ The capital stock is instantaneouly and costlessly adjustable so it is not a state variable.

${ }^{12}$ Since $\omega^{-1}=E\left\{\frac{r-\widetilde{\mu}}{r+\lambda-\widetilde{\mu}}\right\}=1-E\left\{\frac{\lambda}{r+\lambda-\widetilde{\mu}}\right\}$, equation (5) implies that $\omega^{-1} \leq 1$, with strict inequality if $\lambda>0$, and equation (6) implies that $\omega^{-1}>0$. Therefore, since $0<\omega^{-1} \leq 1, \omega \geq 1$, with strict inequality if $\lambda>0$.
} 
composed of two divisions - a capital-owning division that owns $K_{t}$ at time $t$ and a capital-operating division that produces and sells output at time $t$. Because capital can be instantaneously and costlessly bought or sold at a price of one at time $t$, the value of the capital-owning division at time $t$ is $K_{t}$. The value of the capital-operating division, which rents capital (in an amount equal to the amount of capital owned by the capital-owning division) to produce and sell output, is the present value of current and expected future operating profits. Therefore, the value of the firm at time $t$ is

$$
V_{t}=K_{t}+E_{t}\left\{\int_{t}^{\infty} \pi_{t+\tau} e^{-r \tau} d \tau\right\}
$$

As a step toward calculating the present value in equation (26), use equation (16), the independence of $M_{t}$ and $Z_{t}$, and the fact that $M_{t}$ is a martingale to obtain

$$
E_{t}\left\{\pi_{t+\tau}\right\}=(1-\alpha) M_{t} E_{t}\left\{Z_{t+\tau}\right\}
$$

Substituting equation (27) into equation (26) yields

$$
V_{t}=K_{t}+(1-\alpha) M_{t} \int_{t}^{\infty} E_{t}\left\{Z_{t+\tau}\right\} e^{-r \tau} d \tau
$$

We show in Appendix A that the value of the integral on the right hand side of 
equation $(28)$ is ${ }^{13,14}$

$$
\int_{t}^{\infty} E_{t}\left\{Z_{t+\tau}\right\} e^{-r \tau} d \tau=\frac{\omega}{r+\lambda-\mu_{t}} Z_{t}
$$

Note that when the arrival rate $\lambda$ is zero, so that the growth rate of $Z_{t}$ remains $\mu_{t}$ forever, $\omega=1$ and the expected present value of the stream of $Z_{t+\tau}$ in equation (29) is simply $Z_{t} /\left(r-\mu_{t}\right)$. More generally, when the growth rate $\mu_{t}$ varies over time, a high value of $\mu_{t}$ implies a high value of the present value in equation (29).

The value of the firm can now be obtained by substituting equation (29) into equation (28), and recalling from equation (16) that $\pi_{t}=(1-\alpha) Z_{t} M_{t}$, to obtain

$$
V_{t}=K_{t}+\frac{\omega \pi_{t}}{r+\lambda-\mu_{t}}
$$

Equation (30) is equivalent to equation (24) because equation (15) states that $K_{t}=$ $Z_{t} M_{t}^{\frac{1}{\alpha}}$ and equation (16) states that $\pi_{t}=(1-\alpha) Z_{t} M_{t}$.

${ }^{13}$ To derive the present value of $Z_{t+\tau}$ heuristically, let $P_{t}=P\left(\mu_{t}, Z_{t}\right) \equiv \int_{t}^{\infty} E_{t}\left\{Z_{t+\tau}\right\} e^{-r \tau} d \tau$ be the price of a claim on the infinite stream of $Z_{t+\tau}$ for $\tau \geq 0$. The expected return on this claim over an interval $d t$ of time is $Z_{t} d t+E_{t}\left\{d P_{t}\right\}$. Because the path of future growth rates of $Z_{t}$ is independent of the current value of $Z_{t}, P\left(\mu_{t}, Z_{t}\right)$ can be written as $p\left(\mu_{t}\right) Z_{t}$. The expected change in $P_{t}$ is $E_{t}\left\{d P_{t}\right\}=\lambda Z_{t}\left[p^{*}-p\left(\mu_{t}\right)\right] d t+\mu_{t} Z_{t} p\left(\mu_{t}\right) d t$, where $p^{*}$ is the unconditional expectation of $p\left(\mu_{t}\right)$ so the first term is the expected change arising from a new drawing of the growth rate $\mu_{t}$, and the second term reflects the fact (from equation 4) that $E_{t}\left\{d Z_{t}\right\}=\mu_{t} Z_{t} d t$. Setting the expected return equal to the required return $r p\left(\mu_{t}\right) Z_{t} d t$, and solving yields $\left(r+\lambda-\mu_{t}\right) p\left(\mu_{t}\right)=1+\lambda p^{*}$. Therefore,

$$
p\left(\mu_{t}\right)=\frac{1+\lambda p^{*}}{r+\lambda-\mu_{t}} .
$$

Taking the unconditional expectation of both sides of this expression yields $p^{*}=$ $\left(1+\lambda p^{*}\right) E\left\{\frac{1}{r+\lambda-\widetilde{\mu}}\right\}$, which can be rearranged to obtain $p^{*}=\omega E\left\{\frac{1}{r+\lambda-\widetilde{\mu}}\right\}$ since $\omega \equiv$ $\left[E\left\{\frac{r-\widetilde{\mu}}{r+\lambda-\widetilde{\mu}}\right\}\right]^{-1}$. Therefore $1+\lambda p^{*}=\omega$, so $p\left(\mu_{t}\right)=\frac{\omega}{r+\lambda-\mu_{t}}$.

${ }^{14}$ As we show in footnote $13, \omega=1+\lambda p^{*}$ where $p^{*}>0$ because it is the present value of a stream of positive variables. Therefore, $\omega \geq 1$, with strict inequality if $\lambda>0$. Also from footnote 13 , $p^{*}=\omega E\left\{\frac{1}{r+\lambda-\widetilde{\mu}}\right\}>0$. As we show in footnote 12, equations (5) and (6) together imply that $\omega \geq 1$, and equation (5) then is needed for $p^{*}>0$. 


\subsection{Tobin's $Q$}

Tobin's $Q$ is the ratio of the value of the firm to the replacement cost of the firm's capital stock. Since the price of capital is identically equal to one, the replacement cost of the firm's capital stock is simply $K_{t}$. Dividing the value of the firm in equation (30) by $K_{t}$ yields

$$
Q_{t} \equiv \frac{V_{t}}{K_{t}}=1+\frac{\omega}{r+\lambda-\mu_{t}} \frac{\pi_{t}}{K_{t}}>1
$$

Tobin's $Q$ is greater than one because the firm earns rents $\pi_{t}$. In the absence of rents, Tobin's $Q$ would be identically equal to one because the firm can costlessly and instantaneously purchase and sell capital at a price of one. ${ }^{15}$

The presence of positive rents $\pi_{t}$ is sufficient to make Tobin's $Q$ greater than one in our model. However, rents alone do not imply that Tobin's $Q$ will vary over time for a firm. If $Z_{t}$ were to grow at constant rate, so that $\mu_{t}$ were constant, and if the user cost $v_{t}$ were constant, so that $\frac{\pi_{t}}{K_{t}}$ were constant (see equation 12), then equation (31) shows that Tobin's $Q$ would be constant and greater than one. ${ }^{16}$ However, we have modeled both the growth rate $\mu_{t}$ and the user cost $v_{t}$ as stochastic, and equation (31) shows that Tobin's $Q$ is an increasing function of the contemporaneous growth rate $\mu_{t}$ and an increasing function of the contemporaneous value of operating profit per unit of capital (which is proportional to cash flow per unit of capital). Recall from the discussion following equations (15) and (16) that $\frac{\pi_{t}}{K_{t}}$ is higher for small firms than for large firms. Therefore, the value of $Q_{t}$ in equation (31) is higher for small firms than for large firms.

This effect of the growth rate $\mu_{t}$ on $Q_{t}$ illustrates the distinction in the finance

\footnotetext{
${ }^{15}$ Sargent (1980) presents a model without convex adjustment costs in which Tobin's $Q$ can differ from one. In Sargent's model, Tobin's $Q$ can never exceed one because firms are competitive and do not earn rents, and they can always acquire additional capital instantly at a price of one. However, because investment is irreversible in Sargent's model, Tobin's $Q$ can fall below one.

${ }^{16}$ Thus, decreasing returns to scale or market power, as in Alti (2003) and Cooper and Ejarque (2001) are not sufficient to generate our results. Those papers generate time variation in rents with adjustment costs, whereas we allow time variation in growth prospects and eliminate adjustment costs.
} 
literature between growth stocks and value stocks. Value stocks are identified as stocks with high book-to-market ratios, that is, stocks with low values of $Q_{t}$. By contrast, growth stocks are those with high values of $Q_{t}$, which is consistent with equation (31) because an increase in the expected growth rate $\mu_{t}$ increases the right hand side of this equation.

\section{The Effects of Tobin's $Q$ and Cash Flow on In- vestment}

Define $\iota_{t}$ to be the predictable component of the investment-capital ratio at time $t$ in equation (18), so that, ignoring the constant $\frac{1}{2} \frac{1-\alpha}{\alpha^{2}} \sigma_{M}^{2}$,

$$
\iota_{t}=\mu_{t}+\delta_{t}
$$

However, the growth rate $\mu_{t}$ is not observable and the depreciation rate $\delta_{t}$ may not be well measured. In this section, we show that the growth rate $\mu_{t}$ can be written as a function of Tobin's $Q$ and cash flow per unit of capital $c_{t}$, and that the depreciation rate $\delta_{t}$ is related to cash flow $c_{t}$. Thus, to the extent that $Q_{t}$ and $c_{t}$ reflect $\mu_{t}$ and $\delta_{t}$, these variables can help account for movements in investment.

First, we show that the growth rate $\mu_{t}$ can be expressed in terms of the observable variables $Q_{t}$ and $c_{t}$. Use equation (12) to substitute $(1-\alpha) c_{t}$ for $\frac{\pi_{t}}{K_{t}}$ in equation (31) to obtain

$$
Q_{t}=1+(1-\alpha) \omega \frac{c_{t}}{r+\lambda-\mu_{t}} .
$$

Multiply both sides of equation (33) by $r+\lambda-\mu_{t}$ and rearrange to obtain an expression for the growth rate $\mu_{t}$ in terms of the observable values of Tobin's $Q$ and cash flow normalized by the capital stock

$$
\mu_{t}=r+\lambda-(1-\alpha) \omega \frac{c_{t}}{Q_{t}-1}
$$

To express $\iota_{t}=\mu_{t}+\delta_{t}$ as a function of $Q_{t}$ and $c_{t}$, add $\delta_{t}$ to both sides of equation (34), and use the fact from equation (12) that $\alpha c_{t}=v_{t}$ and the definition of the user 
cost $v_{t} \equiv r+\delta_{t}$ to obtain

$$
\iota\left(Q_{t}, c_{t}\right) \equiv\left(\alpha-\frac{(1-\alpha) \omega}{Q_{t}-1}\right) c_{t}+\lambda
$$

We will analyze the effects of $Q_{t}$ and $c_{t}$ on investment by analyzing the effects of these variables on $\iota\left(Q_{t}, c_{t}\right)$.

First we analyze the effect of Tobin's $Q$ on investment for a given level of cash flow $c_{t}$. Let $\beta_{Q} \equiv \partial \iota\left(Q_{t}, c_{t}\right) / \partial Q_{t}$ denote the response of the investment-capital ratio to an increase in $Q_{t}$. Partially differentiating $\iota\left(Q_{t}, c_{t}\right)$ with respect to $Q_{t}$ yields

$$
\beta_{Q} \equiv \frac{\partial \iota\left(Q_{t}, c_{t}\right)}{\partial Q_{t}}=\frac{(1-\alpha) \omega c_{t}}{\left(Q_{t}-1\right)^{2}}>0
$$

so that investment is an increasing function of $Q_{t}$. The positive relationship between investment and Tobin's $Q$ has some remarkable differences from the relationship in the standard convex adjustment cost framework. The positive relationship between investment and $Q_{t}$ arises in the standard framework because of the convexity of the adjustment cost function. For instance, in the special case in which the adjustment cost function is quadratic in investment, the relationship between investment and $Q$ is linear. In that case, in a regression of the investment-capital ratio on $Q_{t}$ and $c_{t}$, the coefficient on $Q_{t}$ is the reciprocal of the second derivative of the adjustment cost function with respect to investment. ${ }^{17}$ This estimated coefficient, which is the analogue of $\beta_{Q}$ in equation (36), is typically quite small, which is usually interpreted to mean that adjustment costs are very large. In the model we present here, investment is positively related to $Q_{t}$, that is, $\beta_{Q}>0$, even though there are no convex costs of adjustment. In addition, it is quite possible for $\beta_{Q}$ to be small (if $(1-\alpha) \omega c_{t}$ is small or if $Q_{t}$ is large). Yet, in this model, without convex adjustment costs, the small value of $\beta_{Q}$ cannot indicate large adjustment costs, as in standard interpretations.

\footnotetext{
${ }^{17}$ In the case with adjustment costs that are quadratic in investment, and linearly homogenous in investment and the capital stock, so that the optimal investment-capital ratio is a linear function of $Q_{t}$, the adjustment cost function $C\left(I_{t}, K_{t}\right)$ can be written as $C\left(I_{t}, K_{t}\right)=\frac{1}{2} b\left(\frac{I_{t}}{K_{t}}\right)^{2} K_{t}$. The coefficient on $Q_{t}$ in an investment regression is $\frac{1}{b}$ in this case. A small value of this coefficient implies that $b$ is large.
} 
Another remarkable difference from standard models based on convex capital adjustment costs is that the investment-capital ratio is related to average $Q, \frac{V_{t}}{K_{t}}$, rather than to marginal $Q, \frac{\partial V_{t}}{\partial K_{t}}$, which equals one in this model. ${ }^{18}$ The relationship between investment and average $Q$ in our model is noteworthy because average $Q$ is observable, whereas marginal $Q$ is not observable. The link between investment and Tobin's $Q$ arises here because, even in the absence of adjustment costs, investment is a dynamic phenomenon. That is, investment is the growth of the capital stock plus depreciation, and the growth of the optimal capital stock depends on $\mu_{t}$, the growth rate of $Z_{t}$. Since $Q_{t}$ also depends on $\mu_{t}$, it contains information about the growth of the capital stock.

Another difference from the standard $Q$-theoretic framework based on convex adjustment costs is that the relationship between investment and $Q$ in our framework is not structural. In the presence of convex adjustment costs, the relation between investment and (marginal) $Q$ is structural in the sense that it is a direct consequence of the first-order condition equating the marginal cost of adjustment and marginal $Q$. However, in the present framework, without convex adjustment costs, the relationship between investment and Tobin's $Q$ is not structural. As emphasized by Sargent (1980) in a different framework without convex adjustment costs, the relationship between investment and $Q$ does not represent any particular underlying cost or preference function, and is sensitive to the stochastic properties of various variables.

Equation (35) has another remarkable feature. Even after taking account of $Q_{t}$ on the rate of investment, investment also depends on normalized cash flow $c_{t}$. Empirical studies of investment often find that the firm's cash flow per unit of capital is positively related to the rate of investment per unit of capital, even when a measure of $Q$ is included as an explanator of investment. A typical empirical equation, starting from Fazzari, Hubbard, and Petersen (1988), would have the investment-capital ratio as the dependent variable, and Tobin's $Q$ and $c_{t}$, the ratio of the firm's cash flow

\footnotetext{
${ }^{18}$ Caballero and Leahy (1996) and Abel and Eberly (1998) analyze optimal investment in the presence of a fixed cost of investment and find that investment is related to average $Q$.
} 
to its capital stock, as the dependent variables. The finding of a positive cash flow effect is often interpreted as evidence of a financing constraint facing the firm.

To analyze the effect of cash flow on investment in our model, let $\beta_{c} \equiv \frac{\partial \iota\left(Q_{t}, c_{t},\right)}{\partial c_{t}}$ denote the response of the investment-capital ratio to an increase in cash flow per unit of capital, $c_{t}$, holding Tobin's $Q$ constant. Partially differentiate equation (35) with respect to $c_{t}$ to obtain

$$
\beta_{c} \equiv \frac{\partial \iota\left(Q_{t}, c_{t}\right)}{\partial c_{t}}=\alpha-\frac{(1-\alpha) \omega}{Q_{t}-1}
$$

The sign of $\beta_{c}$ in equation (37) depends on the magnitudes of two competing factors. Since $r+\delta_{t}=\alpha c_{t}$, a high value of $c_{t}$ indicates that $\delta_{t}$ is high and hence that replacement investment as a fraction of the capital stock is high. This positive effect of cash flow on the investment-capital ratio is captured by the first term, $\alpha$, on the right hand side of equation (37). Working in the opposite direction is the fact that, for a given value of $Q_{t}$, a high value of $c_{t}$ indicates a low value of the growth rate $\mu_{t}$ because $Q_{t}$ is an increasing function of both $c_{t}$ and $\mu_{t}$. The implied low value of $\mu_{t}$ indicates a low growth rate of the capital stock and hence a low value of the investment-capital ratio. This negative effect of cash flow on the investment-capital ratio is captured by the second term, $-\frac{(1-\alpha) \omega}{Q_{t}-1}$, on the right hand side of equation $(37)$.

Use equation (33) to substitute $\frac{(1-\alpha) \omega}{r+\lambda-\mu_{t}} c_{t}$ for $Q_{t}-1$ in equation (37), then use (12) to substitute $\frac{v_{t}}{\alpha}$ for $c_{t}$, and use the definition of the user cost, $v_{t} \equiv r+\delta_{t}$, to obtain the following the expression for $\beta_{c}$

$$
\beta_{c}=\alpha \frac{\mu_{t}+\delta_{t}-\lambda}{r+\delta_{t}}
$$

Condition $2 \delta_{t}+\mu_{t}>\lambda$ for all $t$.

Inspection of equation (38) reveals that Condition 2 is necessary and sufficient for $\beta_{c}>0$.

Henceforth in this discussion we will assume that Condition 2 holds so that $\beta_{c}>0$; note that the condition for a positive cash flow effect is most likely to hold for high 
growth $\left(\right.$ high $\mu_{t}$ ) firms. Although the traditional literature would interpret this positive relationship between cash flow and investment as evidence of a financing constraint, the positive effect arises in this model even though capital markets are perfect and there are no financing constraints. A positive cash flow effect on investment in the absence of financing constraints undermines the logical basis for the common tests of financing constraints in the literature.

The positive time-series relationship between investment and cash flow for a given firm operates through the user cost of capital, $v_{t}$. As we discussed in Section 2, an increase in $v_{t}$ arising from an increase in the depreciation rate, $\delta_{t}$, will increase gross investment relative to the capital stock. As is evident from equation (12), an increase in $v_{t}$ also increases the ratio of cash flow to the capital stock. Thus, the positive time-series association between cash flow and investment reflects the fact that each of these variables moves in the same direction in response to an increase in the user cost of capital.

\section{The Effects of Firm Size and Growth on the Cash Flow Effect}

The empirical literature on investment has found that cash flow has a more significant positive effect on investment for firms that are small or growing quickly. This finding has been interpreted as evidence that these firms face binding financial constraints, while large, slowly growing firms are either less constrained or financially unconstrained. This conclusion is perhaps appealing because it coheres well with the notion that small or rapidly growing firms do not have as much access to capital markets and external financing as large, slowly growing firms have. In this section we show that in our model, the effect of cash flow on investment, measured by $\beta_{c}$, is larger for firms that are small or rapidly growing than for large, slowly growing firms, which is consistent with empirical findings, even though there are no financial constraints in our model. 
Recall from Section 3.1 that small firms have higher $Q_{t}$ than do large firms. Inspection of equation (37) reveals that the cash flow coefficient $\beta_{c}$ is increasing in $Q_{t}$. Therefore, the cash flow coefficient $\beta_{c}$ is higher for small firms than for large firms, which is consistent with the empirical finding that cash flow effects are stronger for smaller firms.

The empirical literature sometimes identifies fast-growing firms as firms likely to face binding financing constraints and finds that these firms have larger cash flow coefficients than slow-growing firms. Inspection of equation (38) reveals that the cash flow coefficient $\beta_{c}$ is an increasing function of the growth rate $\mu_{t}$, which is consistent with the empirical findings. Again, our model without any financing constraints is consistent with empirical findings that have been interpreted as evidence of financing constraints.

\section{Concluding Remarks}

This paper presents a new explanation for the empirical time-series relationship between investment and Tobin's $Q$. Traditional explanations of this relationship are based on convex costs of adjusting the capital stock. In this paper, we have assumed that there are no such adjustment costs that drive a wedge between the purchase price of capital and the market value of installed capital. Instead, the wedge between the market value of a firm and the replacement cost of its capital stock is based on rents accruing to market power or to decreasing returns to scale in the production function. The presence of these rents implies that Tobin's $Q$ exceeds one.

Beyond showing that $Q$ exceeds one, we showed that the investment-capital ratio is positively related to Tobin's $Q$, which is a measure of average $Q$, rather than to marginal $Q$, as in the convex adjustment cost literature. This departure from the adjustment cost literature is particularly important because average $Q$ is readily observable, whereas marginal $Q$ is not directly observable. In the empirical literature, relatively small responses of investment to $Q$ have been taken as evidence of large 
adjustment costs; here there are no adjustment costs at all, and yet the response of investment to $Q$ can be small.

In addition to being consistent with a positive relationship between investment and Tobin's $Q$, the model in this paper can account for the positive effect of cash flow on investment, even when $Q$ is included as an explanator of investment. The common interpretation of the positive cash flow effect on investment is that it is evidence of financing constraints facing firms. However, the model in this paper has perfect capital markets without financing constraints, and yet cash flow can have a positive effect on investment, even after taking account of the effect of $Q$ on investment. Therefore, contrary to the common interpretation, a positive cash flow effect on investment need not be evidence of a financing constraint.

The empirical literature has recognized that the investment regression may be misspecified or mismeasured, leading to spurious cash flow effects. One strategy to address these potentially spurious effects is to split the sample into a priori financially constrained and unconstrained firms. Typically, smaller and faster growing firms, which are often classified a priori as financially constrained, are found to have larger cash flow effects. The same pattern of cash flow effects emerges in our model, even though there are no financing constraints in the model, which calls into question the interpretation of the empirical findings.

The model in this paper is, by design, very simple and stylized. In order for the ratio of cash flow to the capital stock to exhibit time-series variation, the user cost of capital must vary over time, and we induced this variation by allowing the depreciation rate to vary stochastically. In order for Tobin's $Q$ to exhibit time-series variation that is not perfectly correlated with contemporaneous cash flow per unit of capital, we assumed that the growth rate of $Z_{t}$ varies stochastically over time according to a regime-switching model. We eliminated adjustment costs from the current analysis, not because we believe they are irrelevant for an empirical investment model, but rather because they are extraneous to the effects we examine here. The goal of the current paper is to articulate the relationship among investment, Tobin's $Q$, and cash 
flow. Empirical findings regarding these relationships have been used to detect the presence of adjustment costs and financing constraints, and to evaluate their importance for investment. Even when these adjustment costs and financing constraints are eliminated, however, we show that investment remains sensitive to both Tobin's $Q$ and cash flow, undermining traditional interpretations of empirical investment equations. Recent work using numerical modelling (Gomes (2001), Cooper and Ejarque (2003), Eberly, Rebelo, and Vincent (2008)) has cast doubt on whether cash flow effects identify financing constraints. That work shows quantitatively that such effects can arise with perfect capital markets in an empirically misspecified $Q$-theoretic model (with adjustment costs). We show analytically that adjustment costs are not necessary to generate a relationship between investment and $Q$, since rents may arise and importantly, change over time, as the firm's growth rate varies stochastically. Moreover, cash flow effects still arise in this framework, since cash flow moves with the user cost of capital, and hence with investment. Our results show in closed form not only the difficulty of interpreting investment regressions in terms of adjustment costs and financing frictions, but also provide a closed-form alternative interpretation in terms of the firm's growth prospects and the user cost of capital.

An avenue for future research would be to introduce richer and more realistic processes for the various exogenous variables facing the firm. Another direction would be to introduce delivery or gestation lags in the capital investment process. In ongoing research (Abel and Eberly, 2005), we endogenize the growth in technology, summarized here by an exogenous parameter, and similar effects arise in that framework. 


\section{References}

[1] Abel, Andrew B., "Optimal Investment Under Uncertainty," American Economic Review, 73:1 (March 1983), 228-233.

[2] Abel, Andrew B. and Janice C. Eberly, "A Unified Model of Investment Under Uncertainty," American Economic Review, 84:5 (December 1994), 1369-1384.

[3] Abel, Andrew B. and Janice C. Eberly, "The Mix and Scale of Factors with Irreversibility and Fixed Costs of Investment," Carnegie-Rochester Conference Series on Public Policy, 48 (1998), 101-135.

[4] Abel, Andrew B. and Janice C. Eberly, "Investment, Valuation, and Growth Options," revised October 2005.

[5] Alti, Aydogan, "How Sensitive is Investment to Cash Flow When Financing is Frictionless?" The Journal of Finance, 58, 2 (April 2003), 707-722.

[6] Brainard, William and James Tobin, "Pitfalls in Financial Model Building," American Economic Review, 58:2, (May 1968), pp. 99-122.

[7] Caballero, Ricardo and John V. Leahy, "Fixed Costs: The Demise of Marginal q," National Bureau of Economic Research Working Paper No. W5508, March 1996.

[8] Cooper, Russell and Joao Ejarque, "Financial Frictions and Investment: Requiem in Q," Review of Economic Dynamics, Vol. 6 (2003), 710-728.

[9] Eberly, Janice, Sergio Rebelo and Nicolas Vincent, "Investment and Value: A Neoclassical Benchmark," National Bureau of Economic Research Working Paper No. 13866, March 2008.

[10] Erickson, Timothy and Toni M. Whited, "Measurement Error and the Relationship between Investment and 'q'," Journal of Political Economy, Vol. 108, No. 5. (Oct., 2000), 1027-1057. 
[11] Fazzari, Steven, R. Glenn Hubbard and Bruce Petersen, "Finance Constraints and Corporate Investment," Brookings Papers on Economic Activity, 1:1988, $141-195$.

[12] Fazzari, Steven, R. Glenn Hubbard and Bruce Petersen, "Investment-Cash Flow Sensitivities Are Useful: A Comment on Kaplan and Zingales," Quarterly Journal of Economics, 115:2 (May 2000), 695-706.

[13] Gomes, Joao F., "Financing Investment," American Economic Review, 91:5 (December 2001), 1263-1285.

[14] Gomes, Joao F., Amir Yaron, and Lu Zhang, "Asset Pricing Implications of Firms' Financing Constraints," Review of Financial Studies, 19:4 (Winter 2006), 1321-1356.

[15] Jorgenson, Dale W., "Capital Theory and Investment Behavior," American Economic Review, Papers and Proceedings, 53:2 (May 1963), 247-259.

[16] Kaplan, Steven N. and Luigi Zingales, "Do Investment-Cash Flow Sensitivities Provide Useful Measures of Financing Constraints?" Quarterly Journal of Economics, 112:1 (February 1997), 141-168.

[17] Kaplan, Steven N. and Luigi Zingales, "Investment-Cash Flow Sensitivities Are Not Valid Measures of Financing Constraints," Quarterly Journal of Economics, 115:2 (May 2000), 707-712.

[18] Keynes, John Maynard, The General Theory of Employment, Interest, and Money, The Macmillian Press, Ltd., 1936.

[19] Lindenberg, Eric B. and Stephen A. Ross, "Tobin's $Q$ Ratio and Industrial Organization," The Journal of Business, Vol. 54, No. 1. (Jan., 1981), 1-32.

[20] Lucas, Robert E., Jr. and Edward C. Prescott, "Investment Under Uncertainty," Econometrica, 39:5 (September 1971), 659-681. 
[21] Mussa, Michael, "External and Internal Adjustment Costs and the Theory of Aggregate and Firm Investment," Economica, 44:174 (May 1977), 163-178.

[22] Sargent, Thomas J., “Tobin's q' and the Rate of Investment in General Equilibrium," Carnegie-Rochester Conference Series on Public Policy, 12 (Spring 1980), 107-154.

[23] Schianterelli, Fabio, and G. Georgoutsos, "Monopolistic Competition and the Q Theory of Investment," European Economic Review, 34:5 (July 1990), 10611078.

[24] Tobin, James, "A General Equilibrium Approach to Monetary Theory," Journal of Money, Credit, and Banking, 1:1 (February 1969), 15-29. 


\section{A Appendix: Expected Present Value of a Stream with Variable Drift}

Let $P\left(\mu_{t}, Z_{t}\right)=p\left(\mu_{t}\right) Z_{t}$, where $p\left(\mu_{t}\right) \equiv E_{t}\left\{\int_{0}^{\infty} \frac{Z_{t+\tau}}{Z_{t}} e^{-r \tau} d \tau\right\}$. Let $p\left(\mu_{t}, T\right)$ be the value of $p\left(\mu_{t}\right)$ conditional on the assumption that the growth rate of $Z_{t}$ remains equal to $\mu_{t}$ until time $t+T$, and that a new value of the growth rate is drawn from the unconditional distribution at time $t+T$. Therefore,

$$
p\left(\mu_{t}, T\right)=\int_{0}^{T} e^{-\left(r-\mu_{t}\right) \tau} d \tau+e^{-\left(r-\mu_{t}\right) T} E_{t}\left\{\int_{T}^{\infty} \frac{Z_{t+\tau}}{Z_{t+T}} e^{-r(\tau-T)} d \tau\right\} .
$$

Evaluating the first integral on the right hand side of equation (A.1) and rewriting the second integral yields

$$
p\left(\mu_{t}, T\right)=\frac{1-e^{-\left(r-\mu_{t}\right) T}}{r-\mu_{t}}+e^{-\left(r-\mu_{t}\right) T} E_{t}\left\{\int_{0}^{\infty} \frac{Z_{t+T+\tau}}{Z_{t+T}} e^{-r \tau} d \tau\right\} .
$$

Let $p^{*}$ be the expectation of $p\left(\mu_{t}\right)$ when $\mu_{t}$ is drawn from its unconditional distribution, so that equation (A.2) can be written as

$$
p\left(\mu_{t}, T\right)=\frac{1-e^{-\left(r-\mu_{t}\right) T}}{r-\mu_{t}}+e^{-\left(r-\mu_{t}\right) T} p^{*} .
$$

The density of $T$ is

$$
f(T)=\lambda e^{-\lambda T}
$$

and

$$
p\left(\mu_{t}\right)=\int_{0}^{\infty} p\left(\mu_{t}, T\right) f(T) d T .
$$

Substituting equations (A.3) and (A.4) into equation (A.5) yields

$$
p\left(\mu_{t}\right)=\int_{0}^{\infty}\left[\frac{1-e^{-\left(r-\mu_{t}\right) T}}{r-\mu_{t}}+e^{-\left(r-\mu_{t}\right) T} p^{*}\right] \lambda e^{-\lambda T} d T .
$$

Equation (A.6) can be rewritten as

$$
p\left(\mu_{t}\right)=\frac{1}{r-\mu_{t}}\left[\int_{0}^{\infty}\left[1+\left(r p^{*}-\mu_{t} p^{*}-1\right) e^{-\left(r-\mu_{t}\right) T}\right] \lambda e^{-\lambda T} d T\right] .
$$

Evaluating the integral in equation (A.7) yields

$$
p\left(\mu_{t}\right)=\frac{1}{r-\mu_{t}}\left[1+\left(r p^{*}-\mu_{t} p^{*}-1\right) \frac{\lambda}{r+\lambda-\mu_{t}}\right],
$$


which can be rearranged to yield

$$
p\left(\mu_{t}\right)=\frac{1+\lambda p^{*}}{r+\lambda-\mu_{t}}
$$

Since $p^{*}=E\left\{p\left(\mu_{t}\right)\right\}$, take the unconditional expectation of both sides of equation (A.9) to obtain

$$
p^{*}=E\left\{\frac{1}{r+\lambda-\mu_{t}}\right\}\left(1+p^{*} \lambda\right),
$$

which implies

$$
p^{*}=\left[E\left\{\frac{r-\mu_{t}}{r+\lambda-\mu_{t}}\right\}\right]^{-1} E\left\{\frac{1}{r+\lambda-\mu_{t}}\right\} .
$$

Substituting equation (A.11) into equation (A.9) yields

$$
p\left(\mu_{t}\right)=\frac{\omega}{r+\lambda-\mu_{t}}
$$

where

$$
\omega \equiv\left[E\left\{\frac{r-\mu_{t}}{r+\lambda-\mu_{t}}\right\}\right]^{-1} .
$$

Therefore,

$$
P\left(\mu_{t}, Z_{t}\right)=\frac{\omega}{r+\lambda-\mu_{t}} Z_{t}
$$

\section{B Appendix: Verification of the Solution to Equa- tion (23)}

Suppose that the value of the firm is given by equation (24), which we repeat here

$$
V_{t}\left(Z_{t}, M_{t}, \mu_{t}\right)=Z_{t} M_{t}^{\frac{1}{\alpha}}+\frac{(1-\alpha) \omega Z_{t} M_{t}}{r+\lambda-\mu_{t}}
$$

Use Ito's Lemma and the facts that the right hand side of equation (B.1) is linear in $Z_{t}$ and that $M_{t}$ is a martingale to obtain

$$
\begin{aligned}
E_{t}\left\{d V_{t}\right\}= & \mu_{t} Z_{t} M_{t}^{\frac{1}{\alpha}} d t+\frac{1}{2} \frac{1-\alpha}{\alpha^{2}} \sigma_{M}^{2} Z_{t} M_{t}^{\frac{1}{\alpha}} d t \\
& +(1-\alpha) \omega Z_{t} M_{t}\left(\frac{1}{r+\lambda-\mu_{t}} \mu_{t}+\lambda\left[E_{t}\left\{\frac{1}{r+\lambda-\widetilde{\mu}}\right\}-\frac{1}{r+\lambda-\mu_{t}}\right]\right) d t .
\end{aligned}
$$


Use the facts that $E_{t}\left\{\frac{\lambda}{r+\lambda-\widetilde{\mu}}\right\}=1-E_{t}\left\{\frac{r-\widetilde{\mu}}{r+\lambda-\widetilde{\mu}}\right\}$ and $\frac{\mu_{t}-\lambda}{r+\lambda-\mu_{t}}=-1+\frac{r}{r+\lambda-\mu_{t}}$ to rewrite equation (B.2) as

$$
\begin{aligned}
E_{t}\left\{d V_{t}\right\}= & \mu_{t} Z_{t} M_{t}^{\frac{1}{\alpha}} d t+\frac{1}{2} \frac{1-\alpha}{\alpha^{2}} \sigma_{M}^{2} Z_{t} M_{t}^{\frac{1}{\alpha}} d t \\
& +(1-\alpha) \omega Z_{t} M_{t}\left(\frac{r}{r+\lambda-\mu_{t}}-E_{t}\left\{\frac{r-\widetilde{\mu}}{r+\lambda-\widetilde{\mu}}\right\}\right) d t
\end{aligned}
$$

Use equation (B.3) along with equations (20) and (21) to obtain

$E_{t}\left\{R_{t} d t-\left(d K_{t}+\delta_{t} K_{t} d t\right)+d V_{t}\right\}=\left[\begin{array}{c}Z_{t} M_{t}-\delta_{t} Z_{t} M_{t}^{\frac{1}{\alpha}} \\ +(1-\alpha) \omega Z_{t} M_{t}\left(\frac{r}{r+\lambda-\mu_{t}}-E_{t}\left\{\frac{r-\widetilde{\mu}}{r+\lambda-\widetilde{\mu}}\right\}\right)\end{array}\right] d t$

Use the definition of $\omega$ in equation (25) to substitute $\omega^{-1}$ for $E\left\{\frac{r-\widetilde{\mu}}{r+\lambda-\widetilde{\mu}}\right\}$ in equation (B.4) to obtain

$$
E_{t}\left\{R_{t} d t-\left(d K_{t}+\delta_{t} K_{t} d t\right)+d V_{t}\right\}=\left[\alpha Z_{t} M_{t}-\delta_{t} Z_{t} M_{t}^{\frac{1}{\alpha}}+\frac{r(1-\alpha) \omega Z_{t} M_{t}}{r+\lambda-\mu_{t}}\right] d t
$$

Add and subtract $r Z_{t} M_{t}^{\frac{1}{\alpha}}$ on the right hand side of equation (B.5) to obtain

$$
E_{t}\left\{R_{t} d t-\left(d K_{t}+\delta_{t} K_{t} d t\right)+d V_{t}\right\}=\left[\begin{array}{c}
\left(\alpha M_{t}-\left(r+\delta_{t}\right) M_{t}^{\frac{1}{\alpha}}\right) Z_{t} \\
+r\left(\frac{(1-\alpha) \omega Z_{t} M_{t}}{r+\lambda-\mu_{t}}+Z_{t} M_{t}^{\frac{1}{\alpha}}\right)
\end{array}\right] d t
$$

Use the definition $M_{t} \equiv\left(\frac{v_{t}}{\alpha}\right)^{\frac{-\alpha}{1-\alpha}}=\left(\frac{r+\delta_{t}}{\alpha}\right)^{\frac{-\alpha}{1-\alpha}}$ to show that

$$
\alpha M_{t}-\left(r+\delta_{t}\right) M_{t}^{\frac{1}{\alpha}}=0
$$

Substitute equation (B.7) into equation (B.6) to obtain

$$
E_{t}\left\{R_{t} d t-\left(d K_{t}+\delta_{t} K_{t} d t\right)+d V_{t}\right\}=r\left(\frac{(1-\alpha) \omega Z_{t} M_{t}}{r+\lambda-\mu_{t}}+Z_{t} M_{t}^{\frac{1}{\alpha}}\right) d t .
$$

Finally, use equation (B.1) to rewrite the right hand side of equation (B.8) so that

$$
E_{t}\left\{R_{t} d t-\left(d K_{t}+\delta_{t} K_{t} d t\right)+d V_{t}\right\}=r V_{t} d t
$$

which shows that equation (24) is a solution to equation (23). 